\title{
Statt eines Vorwortes
}

Ich bin nicht nur überzeugt,

daß das, was ich sage, falsch ist, sondern auch das, was man dagegen sagen wird.

Trotzdem muß man anfangen, davon zu reden;

die Wahrheit liegt bei einem solchen Gegenstand

nicht in der Mitte,

sondern rundherum wie ein Sack,

der mit jeder neuen Meinung,

die man hineinstopft,

seine Form ändert,

aber immer fester wird.

Robert Musil, Das hilflose Europa, 1922

Europa, so sagen es Politiker aller Parteien und Kommentatoren aller Medien, befinde sich in einer Krise und stelle eine Herausforderung dar, auf die man eine Antwort finden müsse. Europa, so tönt es auf den Straßen einiger Regionen, trage Schuld am sozialen Niedergang der Massen, die Armen würden ärmer und die Reichen reicher. In Europa wachse die Gefahr einer Revolution, orakelt ein Elder Statesman, der erfahren hat, dass Revolutionen sich nicht ganz haben parlamentarisieren lassen. „Raus aus Europa“, drohen die einen, „raus aus Europa“, wünschen sich andere. Und eine immer noch wachsende Zahl von Staaten will nach Europa und in seine Währung, den Euro. Um ihn zu stabilisieren, spannt man für ihn, für die ,Schuldenländer und die Banken immer größere Rettungsschirme auf.

Die Metapher vom ,Rettungsschirm' signalisiert eine gewisse Ratlosigkeit. Selbst unter dem größten Parasol oder Parapluie finden nur wenige Platz, und je größer er ist, umso eher schlägt er um und wird nutzlos, wenn der Sturmwind unter ihn fährt. Aber vielleicht soll man beim Rettungsschirm an einen Parachute denken - er rettet zwar nicht vor dem Fall, setzt ihn geradezu voraus, verzögert ihn jedoch und lindert beim Lapsus lebensrettend den Aufprall.

Wie auch immer: Die Krise Europas ist jedem von uns gegenwärtig, eine tiefgreifende wie folgenreiche Analyse ihrer Ursachen hat noch nicht stattgefunden. Vielleicht lohnt sie die Mühe nicht, da man ahnen mag, dass es zu einer vernunftgesteuerten Besinnung und Orientierung nicht kommen wird.

Schweigsame Skepsis war freilich noch nie hilfreich, weshalb Philosophen wie Jürgen Habermas oder Poeten wie Adolf Muschg das Wort und die Feder zu Europa ergreifen - und sie sind nur die Spitze eines gedankenreichen Eisberges. Es ist, beispielhaft genommen, ein Zeichen des Ernstes 
der Lage, vor allem aber auch ein Zeichen politischer Reife und journalistischen Verantwortungsbewusstseins, wenn die ,Frankfurter Allgemeine Zeitung“ unter dem Titel „Welches Europa wollen wir“ engagierten und sachkundigen Antworten von Politikern, Philosophen, Rechtsgelehrten, Wirtschaftswissenschaftlern oder Poeten über Monate hin breiten Raum gibt.

Der vorliegende Sammelband kann und will damit nicht konkurrieren und soll doch engagiert zum Ausdruck bringen, dass ,Europa‘ ein Thema auch der Wissenschaftsakademien in Deutschland und auch ein Thema der Akademie der Wissenschaften in Hamburg ist, die es sich zur Aufgabe gemacht hat, ein sichtbarer Faktor in der Gestaltung unserer Wirklichkeit zu sein, und dies nicht erst seit heute. Er basiert auf den Vorträgen, die im Winter 2011/2012 im Rahmen der Akademievorlesungsreihe „Deutschland und Europa: Wächst zusammen, was zusammen gehört?“ gehalten wurden.

Nach der Befreiung Deutschlands aus der selbst gewählten Barbarei Hitlers, seiner Helfer und Helfershelfer, kam man in Hamburg zu der Erkenntnis, dass die 1919 neugegründete Universität nicht ernsthaft, jedenfalls nicht wirkungsvoll genug Widerstand geleistet hat gegen ein Regime, das einer freien, demokratisch gesinnten und ihrer eigenen Fehlbarkeit bewussten Wissenschaft grundsätzlich und von Anbeginn an feindlich und vernichtungsbereit gegenüberstand. Als Antwort auf diesen Befund betraute man den so fragilen wie widerständigen und großgesinnten Emil Wolff 1945 mit dem ersten Rektorat der wiedereröffneten Universität und gründete eine Akademie der Wissenschaften, der man ganz bewusst nicht den Rang einer öffentlich-rechtlichen Einrichtung, sondern den staatsunabängigeren Status eines privatrechtlich eingetragenen Vereins zumaß. Der erste Präsident der Joachim JungiusGesellschaft der Wissenschaften e. V. wurde 1947 Bruno Snell. Als er die Nachfolge Wolffs im Rektorat der Universität antrat, übernahm dieser 1949 das Amt des Präsidenten der Akademie.

Kurz vor seinem Tod am 24. Februar 1952 war es Emil Wolff gelungen, den Schweizer Historiker und ehemaligen Präsidenten des Internationalen Roten Kreuzes, Carl J. Burckhardt, nach Hamburg einzuladen. Er sprach über ,Sullys Plan einer Europaordnung،, machte also 1952 in Übereinstimmung mit Emil Wolff und Bruno Snell ,Europa‘ zum Thema der Akademie.

Sullys Plan war freilich nicht geeignet, Vorbild für eine europäische Ordnung nach dem Zweiten Weltkrieg zu sein. Dieser Plan hatte die Vernichtung der Habsburgischen Monarchie und Hegemonie zur Voraussetzung, wie man zwei Jahrhunderte später sich Europa auch nur denken 
konnte, wenn Napoleon besiegt war. An ein Europa mit den Habsburgern oder mit Napoleon konnte wohl niemand denken.

Nach dem Zweiten Weltkrieg gab es zwar Sieger und Besiegte, aber alle Staaten Europas waren zutiefst erschöpft, die Überlebenden aller Nationen sehnten sich gemeinsam nach Frieden.

In dieser Situation gewann Robert Schuman Konrad Adenauer für die Idee, die Sicherung des europäischen Friedens durch vertrauensbildende Maßnahmen, durch die Kontrollierbarkeit kriegswichtiger Güter, Kohle und Stahl, zu ermöglichen. Den Staaten der sich bildenden Gemeinschaft, der Montanunion, blieb die größtmögliche Freiheit bei gleichzeitiger Einbindung in die höchstnötige friedensstiftende und von allen zu tragende gegenseitige Verantwortung.

Europa funktioniert heute sehr anders und so, dass es vielen Bürgern ein Ärgernis ist. Das Verhältnis von Freiheit und Einheit stimmt nicht. Das norwegische Nobel-Komitee hat deshalb Europa den Friedensnobelpreis 2012 verliehen - nicht nur als Auszeichnung für einen oft hart und nicht immer gewaltfrei erkämpften Frieden der europäischen Staaten seit 1945, sondern wohl auch als Ansporn und als Zeichen der Ermutigung für die Zukunft. Zur Einheit Europas, zur verantwortungsvollen Einbettung Deutschlands in dieses Europa gibt es, die Bundeskanzlerin und ihr Finanzminister sagen es ganz zu Recht, keine Alternative. Angela Merkel und Wolfgang Schäuble wären wohl würdige Träger des Nobelpreises gewesen. Aber das Preiskomitee hat weise gehandelt, ganz Europa ausgezeichnet - und in die Pflicht genommen.

Der Wege $\mathrm{zu}$ einem weiterhin friedlichen und Frieden stiftenden Europa gibt es viele, vor allem Frankreich und Deutschland sind auch künftig gefordert, den besten $\mathrm{zu}$ finden, der gewiss keine bequeme Straße, vielmehr ein mühseliger Steig und enger Pfad ist. Die Lektüre des vorliegenden Bandes erleichtert nicht seine Begehbarkeit, erinnert aber aus unterschiedlichen Blickwinkeln an das unaufgebbare Ziel eines gemeinsamen Europas.

Hamburg, im November 2012

Heimo Reinitzer 
